\title{
Transposición Didáctica de la Evolución Biológica: análisis de los libros didácticos
}

\author{
Bianca Guimarães Severo dos Santos \\ severobfg@gmail.com \\ https://orcid.org/0000-0002-6146-4699 \\ Colégio Esadual Lúcia Alves de Oliveira Schoffen \\ Altônia, Brasil \\ Lucila Akiko Nagashima \\ lucilanagashima@uol.com.br \\ https://orcid.org/0000-0001-8197-9668 \\ Universidade Estadual do Paraná - UNESPAR/Campus Paranavaí \\ Paranavaí, Brasil
}

Recibido: 21/03/2021 Aceptado: 22/10/2021

\begin{abstract}
Resumen
El problema de investigación se basó en la siguiente pregunta: ¿cómo se ha discutido el concepto de Evolución Biológica en los libros de texto para que sea enseñado? Así, el objetivo más amplio de esta investigación fue analizar cómo el contenido de la Evolución Biológica, considerado eje unificador en la enseñanza de la Biología, es abordado en algunos trabajos didácticos. Para ello, analizamos quince materiales didácticos desde 1970 hasta 2010, utilizándose tres ejemplares por década. La metodología se basó en el análisis del contenido de la Evolución Biológica, junto con los elementos de la Transposición Didáctica. Los elementos de Transposición Didáctica utilizados en el análisis fueron: fidelidad en la textualización del conocimiento, envejecimiento moral y biológico, relación antiguo / nuevo de conocimiento y creaciones didácticas. Los resultados indicaron que una reformulación curricular de la Educación Superior a la Educación Básica es fundamental para que la enseñanza de la Evolución Biológica contemple la Historia y Filosofía de la Ciencia y sea el eje unificador de todas las áreas de la Biología.
\end{abstract}

Palabras Clave: Libro de texto; Evolución Biológica; Transposición didáctica.

\section{Transposição Didática da Evolução Biológica: uma análise dos livros didáticos}

\section{Resumo}

O problema de pesquisa se baseou no seguinte questionamento: como o conceito de Evolução Biológica tem sido discutido nos livros didáticos para que se torne ensinável? Assim, o objetivo mais amplo desta pesquisa foi o de analisar como o conteúdo de Evolução Biológica, considerado o eixo unificador no ensino de Biologia, é abordado em algumas obras didáticas. Para isso, analisamos quinze materiais didáticos de 1970 a 2010, sendo utilizados três exemplares por década. A metodologia foi baseada na análise do conteúdo de Evolução Biológica, juntamente com os elementos da transposição didática. Os elementos da transposição didática utilizados na análise foram: fidelidade na textualização do saber, envelhecimento moral e biológico, relação antigo/novo do saber e criações didáticas. Os resultados indicaram que é indispensável uma reformulação curricular desde o Ensino 
Superior até a Educação Básica para que o ensino de Evolução Biológica contemple a História e Filosofia da Ciência e seja o eixo unificador de todas as áreas da Biologia.

Palavras Chaves: Livro Didático; Evolução Biológica; Transposição Didática.

\title{
Didactic Transposition of Biological Evolution: an analysis of didactic books
}

\begin{abstract}
The research problem was based on the following question: how has the concept of Biological Evolution been discussed in textbooks in oder to make it teachable? Thus, the broader objective of this research was to analyze how the content of Biological Evolution, considered the unifying axis in the teaching of Biology, is approached in some didactic works. For this purpose, we analyzed fifteen teaching materials from 1970 to 2010, using three copies per decade. The methodology was based on the analysis of the content of Biological Evolution, together with the elements of didactic transposition. The elements of didactic transposition used in the analysis were: fidelity in the textualization of knowledge, moral and biological aging, old / new relationship of knowledge and didactic creations. Results indicated that a curricular reformulation from Higher Education to Basic Education is essential so that teaching Biological Evolution encompasses History and Philosophy of Science and it is also the unifying axis of all areas of Biology.
\end{abstract}

Keywords: Textbook; Biological Evolution; Didactic Transposition.

\section{Introdução}

No final do ano de 2019, fomos impactados pelas notícias de um novo vírus altamente transmissível - o coronavírus - e, a partir dessa data, os casos aumentaram e se disseminaram globalmente, sendo a doença classificada como pandêmica. O mundo parou e diversos países aderiram ao "lockdown" e tivemos que adaptar nossa rotina e tarefas diárias, adotando o home office e o ensino a distância. Os noticiários relataram diversos desabafos de alunos e professores frente aos novos desafios do ensino e aprendizagem por meio dos eixos tecnológicos. Conforme a Unesco,

\footnotetext{
a natural queda na aprendizagem poderá alastrar-se por mais de uma década se não forem criadas políticas públicas que invistam em melhorias de infraestrutura, tecnologias, formação, metodologias e salários, além do reforço da merenda, melhor aproveitamento do tempo, tutoria fora do horário usual das aulas e material adicional, quando possível (UNESCO, 2020).
}

É possível observar nesse cenário a desigualdade social que existe entre os alunos, muitos foram extremamente prejudicados por não possuírem recursos como internet de qualidade, computadores, smartphones, entre outros, que lhes permitissem acesso às aulas online e às atividades a serem realizadas. E, muitos dos que tinham acesso a todas essas tecnologias, também se viram "perdidos", por não dominarem adequadamente o emprego 
das ferramentas e, principalmente, pela falta do contato entre docentes e estudantes, trocando suas vivências, pois os professores e os alunos não tinham mais a escola como seu território.

A dificuldade em utilizar os aparelhos tecnológicos no ensino a distância pode estar fortemente relacionada ao fato de os professores e alunos estarem acostumados em basear suas aulas e atividades no livro didático. O método tradicional continua sendo o mais utilizado pelos sistemas de ensino, todos sentados em fileiras e o intenso uso do material escolar. Diante dessa reflexão, percebemos a importância do professor e dos manuais didáticos no processo de ensino e aprendizagem.

Existem outros recursos pedagógicos utilizados pelos professores, como os tecnológicos, que tiveram grande influência durante o ano de 2020, mas muitas pesquisas revelam que o livro didático é um dos materiais mais utilizados no processo de ensino e aprendizagem. Chartier (1990) e Corrêa (2000) relatam que, em alguns casos, ele se constitui a única referência disponível para professores e alunos desenvolverem suas atividades.

A utilização desse material está presente em nossa sociedade desde o fim do século XIX e início do século XX, quando foi se instituindo, também progressivamente, o ensino seriado e o emprego do método simultâneo. Nesse contexto e com a paulatina implantação do método simultâneo, foi necessária também a produção de materiais pedagógicos especificamente destinados a esse modo de organização do ensino, como quadros-negros, cartazes, materiais de ensino e livros didáticos.

Entretanto, há uma preocupação entre essa ligação do professor com o livro didático e a maneira como ele o utiliza desde o processo de preparação da aula até o momento em que o conhecimento alcança os alunos.

Vasconcelos e Souto (2003) relatam que, historicamente, os livros didáticos têm sido compreendidos como agentes determinantes de currículos, limitando a inserção de novas abordagens e possibilidades de contextualização do conhecimento. Por ser uma ferramenta que contém o conhecimento científico a ser transposto ao conhecimento escolar e às suas demais funções, o livro didático é bastante utilizado para preparação das aulas, já que os professores tomam o seu conteúdo científico como um padrão do que deve ser ensinado (ARAÚJO; PORPINO, 2010). A justificativa principal para este ato é que os conteúdos se apresentam de forma simplificada, numa sequência já organizada de apresentação dos assuntos (SILVA; TRIVELATO, 1999).

Basear-se apenas nesses materiais durante a prática pedagógica é um risco para o desenvolvimento do pensamento científico, tendo em vista que poucos materiais abordam a 
natureza da Ciência de forma que contemple aspectos históricos, culturais, sociais, entre outros.

Além disso, diante das mudanças culturais que observamos no mundo atual em relação ao intenso uso das mídias sociais, precisamos atualizar os níveis de educação e capacitar professores para utilizar essas novas metodologias no processo de ensino e aprendizagem; após essa mudança no cenário escolar através do ensino a distância, percebemos a urgência em oferecer cursos de formação docente continuada e de atualizar os métodos de ensino. Seria o fim do livro didático? Essa parece ser uma realidade não tão distante, pois cada vez mais observamos o uso de aplicativos e livros de acesso online.

Porém, neste artigo, buscamos analisar como os livros didáticos são formulados. Qual o procedimento para que os conteúdos sejam "recortados" para compor esses materiais? Nesse processo, é valorizada a História e Filosofia da Ciência nesses manuais didáticos?

Analisamos como o conteúdo de Evolução Biológica é apresentado nesses materiais e o motivo pela escolha do tema se deve ao fato de a compreensão da Evolução Biológica ser fundamental para o desenvolvimento do pensamento científico no ensino de Biologia.

Almeida e Falcão (2010) relatam que, nos livros didáticos, o tema sobre evolução geralmente está colocado no final, quase sempre precedido da unidade referente à genética. Acreditamos que isso ocorre "propositalmente" para evitar que o tema seja ensinado em salas de aula.

A transposição didática nos livros didáticos é responsável por selecionar o "saber sábio", que é o conhecimento científico produzido nas academias para compor o "saber a ensinar". Ao realizar esse processo de transformação do saber sábio para o saber a ensinar, os autores devem tomar alguns cuidados para evitar simplificações da História e Filosofia da Ciência e dos conceitos evolutivos para que os livros didáticos não se tornem materiais de veiculação de uma pseudociência, pois encontramos nos bastidores da maioria das escolas de todo o Brasil professores que se baseiam no material didático para desenvolver as suas aulas, planejamentos ou atividades e tal fato é observado pela facilidade de acesso pela maioria dos professores.

Portanto, o objetivo geral da pesquisa foi investigar como o conteúdo de Evolução Biológica, considerado o eixo unificador do ensino de Biologia, foi abordado em algumas obras didáticas das décadas de 1970 a 2010. 
Neste artigo, vamos analisar os seguintes elementos da transposição didática no conceito de Evolução Biológica de alguns livros didáticos: fidelidade na textualização, envelhecimento biológico e moral, relação antigo/novo do saber e criações didáticas.

\section{Transposição Didática}

Independente das mudanças que possam ocorrer no método de utilização do livro didático - físico ou digital -, para que esses sejam formulados, passam por um processo denominado transposição didática. Os manuais didáticos, durante a sua formulação, obedecem aos parâmetros curriculares definidos pelo governo, que estabelece aquilo que se deve ser ensinado nas redes de ensino do país. Os editores procuram seguir à risca as orientações curriculares contidas nesses guias, objetivando agradar os consumidores de sua mercadoria, ou seja, o próprio Estado, que é o principal comprador de livros didáticos no Brasil (THOMAZ, 2012).

A transposição didática é a ferramenta utilizada para selecionar os conteúdos que serão inseridos na grade do manual didático. Chevellard foi o responsável por aprofundar seus estudos sobre o tema, trazendo algumas contribuições como a diferenciação entre Transposição Didática Externa (TDE), que corresponde às instituições e aos especialistas encarregados de selecionar os conteúdos para compor os materiais didáticos ensinados nas escolas, e a Transposição Didática Interna (TDI), que envolve os participantes do processo de ensino e aprendizagem e exige a autonomia do professor no momento de estudar, reformular e explanar o conteúdo exigido.

A TDE é composta pelo saber sábio, que é o primeiro saber produzido, resultado de pesquisas em academias, institutos, grupos de pesquisas, em diversos temas e áreas distintas (PINHO ALVES FILHO, 2000b); e pelo saber a ensinar, que é um produto organizado e hierarquizado em grau de dificuldade, resultante de um processo de total descontextualização e degradação do saber sábio e feito por meio dos livros-textos e manuais de ensino (PINHO ALVES FILHO, 2000b).

Apresenta-se na TDI o saber ensinado, que corresponde ao que será ensinado pelos professores no processo de ensino e aprendizagem. Nesse novo saber, é mais evidente a interferência das concepções pessoais do professor, dos interesses e opiniões da administração escolar, dos alunos e da comunidade em geral (PINHO ALVES FILHO, 2000a).

Porém, durante esse processo de transformação, ocorre uma certa demora para um saber ser atualizado e compor os materiais didáticos. Um exemplo muito comum é do determinismo genético, em que a maioria dos manuais escolares de diversos países continua 
a referir a influência do genótipo sobre o fenótipo, esquecendo a influência do ambiente na expressão fenotípica (CARVALHO, 2009).

\section{Evolução Biológica}

O estudo e a compreensão da Evolução Biológica são importantes aliados no processo de ensino e aprendizagem da Biologia; estudar os seres vivos e suas características à luz da evolução é um dos objetivos propostos pelo Parâmetro Curricular Nacional para o Ensino Médio (PCENEM). As orientações dos PCNEM descrevem a evolução como tema unificador da Biologia (BRASIL, 2006).

Embora seja uma orientação prevista pelos documentos oficiais, essa não é a realidade observada em salas de aulas. Bizzo e El-Hani (2009) alertam que o formato curricular atual apresenta a temática Evolução Biológica como assunto para o último ano do Ensino Médio, dificultando a construção desse conceito devido ao pouco tempo para aprofundá-lo e a enorme quantidade de conteúdos correlatos que são relevantes para o entendimento do processo evolutivo. Por ser um assunto "polêmico", um dos motivos de estar presente no último tópico do terceiro ano do Ensino Médio é justamente para evitá-lo, ou esquivar do tema.

Sendo o conceito de evolução organizador de outros conteúdos na disciplina de Biologia, é evidente a importância de o professor ter esse conceito bem fundamentado em seu pensamento (MEGLHIORATTI, 2004). Porém, percebemos que há falhas no formato curricular desde o curso de licenciatura em Ciências Biológicas, pois o tema evolução, que deveria ser o eixo norteador de todas as outras disciplinas e, portanto, estar presente no primeiro ano da graduação, encontra-se geralmente no último ano, com uma carga horária insuficiente para desenvolver todos os conceitos que permeiam a definição da Evolução Biológica (MEGLHIORATTI, 2004).

A evolução deveria ser um tema interdisciplinar entre as disciplinas de Biologia, mas, em muitos casos, o professor possui uma defasagem em sua formação decorrente da estruturação da grade curricular estabelecida e tende a transmitir aos seus alunos aquilo que ele aprendeu em sala de aula, ou seja, se durante a graduação não houve uma relação do tema evolução com todas as áreas de conhecimento biológico, dificilmente isso será uma realidade na sua prática pedagógica.

Almeida e Falcão (2010) observam que é frequente nos livros didáticos de Biologia adotados no Brasil a abordagem do tema como: 
concluído, desprovido de contextualização histórica para a compreensão, por parte dos alunos, de como os conceitos foram desenvolvidos ao longo do tempo. E as dificuldades e obstáculos que os estudantes têm de compreender a evolução orgânica estão relacionados à simplificação da transposição das suas teorias para o ambiente escolar (ALMEIDA; FALCÃO, 2010, p. 650).

Esses fatores interferem na formação dos alunos que concluem o Ensino Médio com uma concepção de evolução muito distante da realidade ou até mesmo concepções equivocadas devido à falta de contextualização. Um exemplo clássico é desmerecer Lamarck pela sua teoria do lamarckismo, sendo que ele foi um dos precursores no estudo da evolução e o responsável por instigar a mudança de pensamento da época. Martins (1997) critica a história do tema sobre lamarckismo contida nos livros didáticos de Biologia, para ele há uma desfragmentação e simplificação que prejudica a compreensão da História e Filosofia da Ciência na Evolução Biológica.

Para mudar esse paradigma entorno do ensino de evolução, Meglhioratti (2004) defende que o conhecimento biológico deve estar amparado em três vertentes: (1) no conceito de Evolução Biológica como eixo unificador dos conteúdos a serem ministrados, (2) nas relações ecológicas que se dão entre os seres vivos e o meio ambiente e (3) no contexto histórico no qual os conceitos biológicos foram formulados, ou seja, na História da Biologia.

Concordamos com os autores, a História e Filosofia da Ciência são fundamentais para compreender o desenvolvimento do pensamento científico e para a criticidade do acadêmico que virá a se tornar um professor e desenvolver o conhecimento em seus alunos e, para que isso aconteça, é necessária uma reformulação curricular que abranja todos os níveis de ensino.

\section{Metodologia}

Esta pesquisa possui caráter qualitativo e utilizou como base a análise do conteúdo de Evolução Biológica em livros didáticos do terceiro ano do Ensino Médio das décadas de 1970 a 2010. A pesquisa qualitativa é descritiva e frequentemente reconta quem disse o que, para quem, como, quando e porquê; mas também busca explicar observações realizadas, fornecendo percepções fundamentadas, mostrando quais conceitos e teorias atuam em conjunto em casos particulares. Também na pesquisa qualitativa, o pesquisador faz uma avaliação pessoal dos dados, na definição das categorias e interpretação dos dados coletados, sendo essa a metodologia selecionada para a presente pesquisa.

O primeiro passo foi selecionar os livros didáticos para serem analisados e os critérios utilizados para a escolha foram: 
1. Livros didáticos do terceiro ano do Ensino Médio que continham o conteúdo de Evolução Biológica;

2. Disponibilidade dos livros na Biblioteca Municipal de Nova Esperança e na Biblioteca do Colégio Estadual São Vicente de Paula - EFMNPR, no município de Nova Esperança - PR.

Foram selecionados três livros de cada década, com base na disponibilidade apresentada no acervo das bibliotecas, a partir de 1970 a 2010, e que estão listados no Quadro 1.

Quadro 1 - Relação dos livros analisados.

\begin{tabular}{|c|c|c|c|c|}
\hline Década & Título do Livro & Autor (es) & $\begin{array}{c}\text { Ano de } \\
\text { publicação }\end{array}$ & $\begin{array}{l}\text { Código } \\
\text { do livro }\end{array}$ \\
\hline 1970 & Biologia & Albino Fonseca & 1971 & LD1 \\
\hline 1970 & Biologia & Albino Fonseca & 1977 & LD2 \\
\hline 1970 & Biologia - Volume 3 & $\begin{array}{l}\text { Amabis Martho e } \\
\text { Mizuguchi }\end{array}$ & $1978-1979$ & LD3 \\
\hline 1980 & Biologia 3 & Cesar e Sezar & 1984 & LD4 \\
\hline 1980 & Biologia Básica & Ayrton César Marcondes & 1984 & LD5 \\
\hline 1980 & $\begin{array}{c}\text { Biologia Básica: } \\
\text { volume } 3 \text { - Genética, } \\
\text { Evolução Ecologia }\end{array}$ & José Luís Soares & 1988 & LD6 \\
\hline 1990 & $\begin{array}{c}\text { Biologia - Volume } \\
\text { único }\end{array}$ & $\begin{array}{l}\text { Demétrio Gowdak e } \\
\text { Neide S. de Matos }\end{array}$ & 1991 & LD7 \\
\hline 1990 & $\begin{array}{c}\text { Biologia Hoje: } \\
\text { Volume } 3- \\
\text { Genética, Evolução } \\
\text { Ecologia }\end{array}$ & $\begin{array}{l}\text { Sérgio Linhares e } \\
\text { Fernando } \\
\text { Gewandsznadjder }\end{array}$ & 1993 & LD8 \\
\hline 1990 & $\begin{array}{c}\text { Biologia Atual: } \\
\text { Volume } 3 \text { - Genética } \\
\text { Evolução, Ecologia }\end{array}$ & Wilson Roberto Paulino & 1998 & LD9 \\
\hline 2000 & $\begin{array}{c}\text { Fundamentos da } \\
\text { Biologia Moderna: } \\
\text { Volume único }\end{array}$ & Amabis e Martho & 2002 & LD10 \\
\hline 2000 & $\begin{array}{c}\text { Biologia: Volume } 3 \\
\text { - Biologia das } \\
\text { populações }\end{array}$ & $\begin{array}{c}\text { José Mariano Amabis e } \\
\text { Gilberto Rodrigues } \\
\text { Martho }\end{array}$ & 2004 & LD11 \\
\hline 2000 & $\begin{array}{c}\text { Biologia: Volume } \\
\text { único }\end{array}$ & $\begin{array}{c}\text { Sônia Lopes e Sergio } \\
\text { Rosso } \\
\end{array}$ & 2005 & LD12 \\
\hline 2010 & $\begin{array}{c}\text { Novas Bases da } \\
\text { Biologia: O ser } \\
\text { humano e o futuro }\end{array}$ & Nélio Bizzo & 2010 & LD13 \\
\hline 2010 & Biologia Moderna & $\begin{array}{c}\text { José Mariano Amabis e } \\
\text { Gilberto Rodrigues } \\
\text { Martho }\end{array}$ & 2016 & LD14 \\
\hline 2010 & Contato Biologia & $\begin{array}{c}\text { Marcela Ogo e Leandro } \\
\text { Godoy }\end{array}$ & 2016 & LD15 \\
\hline
\end{tabular}

Fonte: Elaboração pelas autoras. 
Utilizamos alguns elementos da transposição didática de Chevellard para analisar os conteúdos e estabelecer relações e os exames dos livros didáticos foram efetuados através da proposição de perguntas. Esses elementos foram baseados nos trabalhos de Silva (2017), Neves (2009) e Melzer (2012).

A descrição dos elementos e as perguntas utilizadas na discussão das características apresentadas pelos livros didáticos estão relatadas no Quadro 2.

Quadro 2 - Descrição dos elementos da TD e perguntas da análise.

\begin{tabular}{|c|c|}
\hline DESCRIÇÃO DOS ELEMENTOS & $\begin{array}{c}\text { PERGUNTAS FORMULADAS NA } \\
\text { ANÁLISE }\end{array}$ \\
\hline $\begin{array}{l}\text { Fidelidade na textualização: está associado se } \\
\text { as omissões existentes no livro didático podem } \\
\text { prejudicar a compreensão do tema. }\end{array}$ & $\begin{array}{l}\text { 1) Qual o nível de fidelidade ao texto que o } \\
\text { livro aborda sobre a Evolução Biológica? }\end{array}$ \\
\hline $\begin{array}{l}\text { Envelhecimento biológico e moral: o } \\
\text { envelhecimento nos remete a algo que está } \\
\text { ultrapassado. É definido como um desgaste } \\
\text { natural do saber ensinado quando o } \\
\text { enfraquecimento ocorre em relação às } \\
\text { exigências da sociedade. Paralelamente, trata } \\
\text { das definições, conceitos, teorias científicas } \\
\text { que, com o passar do tempo ou com uma } \\
\text { mudança de paradigma, tornam-se obsoletas. }\end{array}$ & $\begin{array}{l}\text { 2) Ao longo da história, o saber é } \\
\text { reestruturado para atender a certas } \\
\text { demandas sociais? Ele cumpre com a } \\
\text { exigência social da época? }\end{array}$ \\
\hline $\begin{array}{l}\text { Relação antigo/novo do saber: é quando se } \\
\text { estabelece uma relação entre um conhecimento } \\
\text { antigo com um mais atualizado. }\end{array}$ & $\begin{array}{l}\text { 3) O livro desenvolve uma explicação sobre a } \\
\text { teoria aceita antes de justificar a teoria da } \\
\text { evolução? Há uma demora na atualização? }\end{array}$ \\
\hline $\begin{array}{l}\text { Criações didáticas: podem ser entendidas } \\
\text { como objetos didáticos que são gerados e } \\
\text { introduzidos na matriz curricular com o } \\
\text { objetivo de auxiliar na aprendizagem de } \\
\text { conceitos. }\end{array}$ & $\begin{array}{l}\text { 4) Os livros apresentam criações didáticas } \\
\text { para facilitar a compreensão da evolução } \\
\text { biológica? Quais as contribuições dessas } \\
\text { imagens? }\end{array}$ \\
\hline
\end{tabular}

Fonte: Elaboração pelas autoras.

\section{Análises e Resultados}

Nesta seção, abordamos os resultados e a discussão obtidos com base na análise dos livros didáticos de Biologia do Ensino Médio. Utilizamos os elementos da transposição didática para verificar como os conhecimentos são transpostos até estarem disponíveis nos materiais didáticos e serem utilizados pela comunidade escolar.

\section{Fidelidade na textualização do saber}

Segundo Silva (2017), a fidelidade do saber está associada se as omissões existentes no livro didático podem prejudicar a compreensão do tema. Melzer (2012) ainda ressalta que 
a fidelidade na textualização procura identificar as modificações e adaptações feitas ou se tal conceito foi apresentado com fidelidade de informações.

A fidelidade está relacionada aos recortes do conteúdo para compor os materiais didáticos, se existem omissões nos conteúdos que possam prejudicar o entendimento do todo. Para investigar esse elemento, foi proposta a seguinte questão: “1. Qual o nível de fidelidade ao texto que o livro aborda sobre a Evolução Biológica?"

Com base na análise dos materiais, observamos que, geralmente, a Evolução Biológica não é interpretada com total fidelidade do saber, os livros didáticos não trazem informações suficientes para a sua total compreensão. Citamos alguns exemplos que demonstram isso:

O LD9 (p. 149) relata que "o Neodarwinismo ou mutacionismo constitui uma ampliação das ideias de Darwin”. Essa é uma interpretação contraditória, pois o mutacionismo e o neodarwinismo são duas teorias diferentes.

Bizzo (1991) chama a atenção para o cuidado do uso de recursos metafóricos dentro do ensino de evolução, pois podem gerar concepções equivocadas. Por exemplo: "como resultado da luta pela vida, haveria a seleção natural dos mais aptos em prejuízo dos menos aptos" (LD6, p. 95); "a natureza age selecionando os mais aptos, a este processo Darwin designou seleção natural” (LD5, p. 124). Sobre isso, Bizzo (1991) faz o seguinte comentário:

\footnotetext{
em primeiro lugar, "a Natureza" não seleciona; ela não possui atributos essencialmente humanos para que pudesse exercer tal ação. Em segundo lugar, os mais aptos não são os escolhidos. Aqueles que não reúnem condições suficientes para sobrevier ou reproduzir-se é que aparecem em números decrescentes em gerações seguintes. Portanto, a imagem de indivíduos bem adaptados sendo identificados e favorecidos por uma entidade tem apenas sentido metafórico (p. 279).
}

Essas frases metafóricas são comumente faladas por professores de Biologia durante a transmissão do conhecimento e disseminada entre os alunos e uma informação, após ser consolidada na mente, torna-se mais trabalhosa a sua modificação. Muitos livros didáticos reforçam essa concepção ao redigir textos que confundem a interpretação correta.

Bizzo e El-Hani (2009) relatam que alguns exemplos de evolução popularmente conhecidos, como o melanismo industrial em mariposas e a resistência de bactérias a antibióticos, são exemplos de microevolução, que dificilmente teriam paralelos em exemplos extraídos dos originais de Darwin. Disso resulta uma tensão no currículo, uma vez que adotar uma perspectiva histórica nos levaria a valorizar escritos originais, mas esses são, ao fim e 
ao cabo, substituídos por textos modernos. Alguns desses exemplos foram encontrados nos livros LD3, LD4, LD6, LD7, LD8, LD11, LD12 e LD14.

Outro fator comumente encontrado nos LDs é a versão que diz que a fusão entre as teorias de Darwin e Mendel não foi realizada enquanto eles estavam em vida apenas porque o trabalho de Mendel não chegou às mãos de Darwin. Bizzo (1991) defende que essa informação é factualmente incorreta: o trabalho de Mendel passou pelas mãos de Darwin, pelo menos em 1869. Porém, a Ciência está em constante construção e esse fato demonstra que ela não é feita por gênios, mas sim por pesquisadores que estão fadados a erros e acertos.

Em seu trabalho, Bizzo (1991) observou que tradicionalmente atribui-se a Lamarck a visão do "senso comum" e a Darwin a visão "científica". Esse pensamento é decorrente principalmente da teoria do lamarckismo e o exemplo do pescoço das girafas: "este foi o principal fator da não aceitação da teoria de Lamarck" (LD3, p. 163). Essa característica pode ser observada nos livros LD1 e LD3, por exemplo, que não valorizam os méritos e as contribuições de Lamarck, focando apenas nos seus erros.

Martins (1998) não concorda com essa simplificação e faz, no trabalho citado, uma forte crítica à História da Ciência contida nos livros didáticos de Biologia. O autor defende a leitura de todas as obras de Lamarck, comparando-as e não tomando como base de sua teoria apenas uma delas. Outra crítica referente ao Lamarckismo é:

em primeiro lugar, a teoria de Lamarck não é uma mera hipótese de herança do adquirido ou aquilo que atualmente se chama lamarckismo. Além disso, tal hipótese ocupa um lugar secundário na teoria de Lamarck. A herança dos caracteres adquiridos é uma ideia muito anterior a Lamarck que continuou a ser aceita em sua época (MARTINS, 1998, p. 19).

Sobre isso, Bizzo (1991, p. 259) afirma:

que a identificação direta e imediata entre a crença na herança das características adquiridas e a teoria de Lamarck é, antes de tudo, um equívoco. Pois, não se pode ligar a crença de toda uma época ao pensamento de uma só pessoa. Opina o mesmo autor ser estranho que Lamarck seja lembrado, inclusive por professores de Biologia, como criador da crença na herança dos caracteres adquiridos - o que não é verdade - e não seja conhecido por ter sido o criador do termo Biologia para designar uma nova disciplina - o que é verdade.

Lamarck contribuiu e influenciou o pensamento da época, portanto, apesar de a sua teoria não ser aceita atualmente, foi através dele que os paradigmas foram superados e que 
a ciência avançou para novas descobertas, por isso atribuir a ele o senso comum não condiz com a construção do conhecimento científico focado na História e Filosofia da Ciência.

\section{Envelhecimento biológico e moral}

Este aspecto revela a desatualização dos saberes que acontece quando os conhecimentos científicos não atendem às necessidades da sociedade. $\mathrm{O}$ termo envelhecimento nos remete a algo que está ultrapassado, desatualizado e é justamente isso que Chevellard ressalta nesse elemento da transposição didática, evidenciando que o conhecimento é mutável e perpassa por três etapas dos saberes.

O processo da transposição didática tem responsabilidades, dentre elas a de fazer com que o saber que chega até a sala de aula seja interpretado e entendido pelo aluno, em uma linguagem condizente à geração que o estuda (NEVES, 2009). Para atender a esse elemento, elaboramos o seguinte questionamento: "2. Ao longo da história, o saber é reestruturado para atender a certas demandas sociais?" E o Quadro 3 sintetiza os resultados.

Quadro 3 - Análise do Envelhecimento biológico e moral.

\begin{tabular}{|c|c|c|}
\hline \multirow{2}{*}{ Código do livro } & \multicolumn{2}{|c|}{ O saber é atualizado para atender a sociedade da } \\
\cline { 2 - 3 } & Sim & Não \\
\hline LD1 & & $\mathrm{X}$ \\
\hline LD2 & $\mathrm{X}$ & $\mathrm{X}$ \\
\hline LD3 & & $\mathrm{X}$ \\
\hline LD4 & & $\mathrm{X}$ \\
\hline LD5 & & $\mathrm{X}$ \\
\hline LD6 & & $\mathrm{X}$ \\
\hline LD7 & & $\mathrm{X}$ \\
\hline LD8 & $\mathrm{X}$ & \\
\hline LD9 & & $\mathrm{X}$ \\
\hline LD10 & & $\mathrm{X}$ \\
\hline LD11 & $\mathrm{X}$ & $\mathrm{X}$ \\
\hline LD12 & & $\mathrm{X}$ \\
\hline LD13 & & \\
\hline LD14 & & \\
\hline LD15 & & \\
\hline
\end{tabular}

Fonte: Elaboração pelas autoras. 
Dos quinze livros analisados, apenas quatro se preocuparam em contemplar os conhecimentos evolutivos de acordo com cada época. Os livros da década de 1970 (LD1 e LD2) não abordam o Neodarwinismo nem citam o contexto histórico para o desenvolvimento das teorias de Lamarck e Darwin, não apresentam também imagens ou representações que possam contribuir para o ensino e aprendizagem. Esse saber está desatualizado para atender as demandas sociais de sua época.

O livro LD4 também não apresenta o neodarwinismo, cita apenas que: "a ideia de seleção natural, acrescida dos conceitos modernos sobre variabilidade (mutação e recombinação) e genética de populações, explica o mecanismo evolutivo. Tais ideias constituem o Neodarwinismo" (LD4, p. 138). E, em outro capítulo, o autor explica sobre a mutação e a recombinação gênica; em um segundo capítulo, sobre a seleção e adaptação; e em um terceiro capítulo, sobre a genética de populações, mas em nenhum momento explica a relação desses conhecimentos para o desenvolvimento da Teoria Sintética da Evolução.

O livro LD5 relata que "à combinação da teoria evolutiva com as causas de ordem genética que a explicam dá-se o nome de Neodarwinismo ou Teoria Sintética da Evolução" (LD5, p. 124). Em seguida, dedica um parágrafo para explicar as mutações e outro para recombinação gênica e, por fim, descreve sobre a genética de populações. Porém, mais uma vez, observamos que não há relação desses saberes com o desenvolvimento da Teoria Sintética da Evolução. Os livros apenas relatam que a união da teoria proposta por Darwin com os conceitos modernos, principalmente da área da Genética, resultou na Teoria Sintética da Evolução, os autores se preocupam em definir esses conceitos, não os contextualizando na construção do conhecimento evolutivo aceito atualmente.

O livro LD7 relata as teorias do Lamarckismo e Darwinismo e, em seguida, dedica um tópico para explicar a seleção natural, a adaptação e a especiação. Não há explicações sobre a Teoria Sintética da Evolução. O livro LD8, ao relatar sobre a Teoria Sintética da Evolução, explica a mutação, variedade e a seleção natural. Em outro capítulo, explica sobre a Genética das populações e a formação de novas espécies. Trata-se de um material bem completo. No livro LD9, encontramos o desenvolvimento do mutacionismo e neodarwinismo como sendo a mesma teoria.

Segundo Cicillini (1991), considera-se como processos básicos da evolução a mutação, a recombinação gênica, a seleção natural e o isolamento reprodutivo e, como processos acessórios, a migração de indivíduos, a hibridação em raças ou espécies estreitamente relacionadas e os efeitos do acaso atuando em populações pequenas (também conhecido como deriva ou oscilação genética). Os livros LD10, LD12, LD13 e LD14 não 
abordam alguns desses processos, que são importantes para a compreensão da evolução, representando um envelhecimento do saber.

Observamos em todos os livros que os capítulos referentes à Teoria Sintética da Evolução estão desatualizados e sofreram um envelhecimento moral e biológico do saber. Em nenhum dos livros são feitas referências sobre descobertas atuais da evolução. Segundo Cicillini (1991), essa simplificação pode apresentar erros de conceituação na medida em que simplificam demais a exposição dos diferentes assuntos.

\section{Relação antigo/novo do saber}

A relação antigo/novo é uma articulação entre os saberes antes desenvolvidos com os saberes mais atualizados. Pena (2014, p. 50) afirma que "o conhecimento apresentado como novo deve possibilitar que os alunos estabeleçam relações com seus conhecimentos anteriores para que seja possível a aprendizagem, aparecendo, portanto, como um objeto antigo". A análise para os questionamentos: “3. O livro desenvolve uma explicação sobre a teoria aceita antes de justificar a teoria da evolução? Há uma demora na atualização?” resultou na elaboração do Quadro 4.

Quadro 4 - Análise da relação antigo/novo do saber associados a Teoria da Evolução

\begin{tabular}{|c|c|c|c|}
\hline \multirow[t]{2}{*}{ Código do livro } & \multicolumn{2}{|c|}{$\begin{array}{l}\text { O livro desenvolve uma explicação sobre a teoria } \\
\text { aceita antes de justificar a teoria da evolução? }\end{array}$} & \multirow{2}{*}{$\begin{array}{l}\text { Há uma demora } \\
\text { na atualização? }\end{array}$} \\
\hline & Sim & Não & \\
\hline LD1 & & $\mathrm{X}$ & Sim \\
\hline LD2 & & $\mathrm{X}$ & Sim \\
\hline LD3 & $\mathrm{X}$ & & Não \\
\hline LD4 & $\mathrm{X}$ & & Não \\
\hline LD5 & $\mathrm{X}$ & & Não \\
\hline LD6 & $\mathrm{X}$ & & Não \\
\hline LD7 & $\mathrm{X}$ & & Não \\
\hline LD8 & $\mathrm{X}$ & & Não \\
\hline LD9 & & $\mathrm{X}$ & Sim \\
\hline LD10 & $\mathrm{X}$ & & Não \\
\hline LD11 & $\mathrm{X}$ & & Não \\
\hline LD12 & $\mathrm{X}$ & & Não \\
\hline LD13 & $\mathrm{X}$ & & Não \\
\hline LD14 & $\mathrm{X}$ & & Não \\
\hline LD15 & $\mathrm{X}$ & & Não \\
\hline
\end{tabular}

Fonte: Elaboração pelas autoras. 
Dos quinze livros pesquisados, apenas em três (LD1, LD2 e LD9) os autores não "resgatam" as ideias ou concepções aceitas anteriormente à consolidação da teoria da evolução e não situam o contexto histórico predominante da época. Ou seja, a maioria dos livros apresenta as teorias aceitas anteriormente, portanto, não há uma demora na atualização nesse quesito em doze dos livros analisados. Os LD1 e LD2 só relatam a existência de duas teorias: Teoria do Criacionismo e Teoria do Evolucionismo, porém, não há uma explicação de como o fixismo era uma corrente aceita pela maioria. Ao omitir essa contextualização, omite-se, também, os problemas enfrentados, os paradigmas existentes resultam em uma concepção desprovida da História e Filosofia da Ciência.

A reflexão sobre a importância de se estudar História e Filosofia é manifestado por Gil Pérez et al. (2001, p.131):

[...] transmitem-se os conhecimentos já elaborados, sem mostrar os problemas que lhe deram origem, qual foi a sua evolução, as dificuldades encontradas, etc., e não dando igualmente a conhecer as limitações do conhecimento científico atual nem as perspectivas que, entretanto, se abrem.

O ensino e aprendizagem com foco na História e Filosofia da Ciência rompe diversos paradigmas e tem um efeito positivo na construção do conhecimento científico de alunos e professores. No LD9, o autor introduz o conteúdo do tema, relatando as teorias propostas por Lamarck e Darwin, não evidenciando que as ideias prevalentes na época eram fixistas e criacionistas.

$\mathrm{Na}$ obra LD4, os autores, além de apresentar a ideia do fixismo proposta na época, citam também o transformismo gradual das espécies, conceituação aceita por alguns pesquisadores da época. Observa-se que em outros livros (LD3, LD4, LD8, LD10, LD11, LD12, LD13, LD14 e LD15), os autores retomam, de alguma forma, o contexto histórico e os embasamentos aceitos e predominantes antes de se estabelecer a Evolução Biológica.

Citamos, a seguir, alguns exemplos:

O criacionismo é uma visão que surgiu há pouco mais de dois séculos e foi o pensamento predominante entre a Idade Média e o século XIX. (LD15, 2016, p.113). (Grifo nosso).

A teoria fixista dominou o mundo científico até meados do século XIX quando foram publicados os princípios da teoria da evolução, 
de autoria dos naturalistas Charles Darwin e Alfred Russel Wallace. [...] A teoria fixista que admitia que os seres não se alteraram, desde que foram criados por inspiração divina, caiu em descrédito com a publicação do livro On the Origin of Species. (LD3, 1978-79, p. 162). (Grifo nosso).

Até o século XVIII, prevaleceram as ideias criacionistas e fixistas, ou seja, a crença na criação divina e na imutabilidade das espécies. (LD7, 1991, p. 381). (Grifo nosso).

Retomar as ideias propostas anteriormente é fundamental para situar o aluno e envolvê-lo no contexto histórico da época, para que ele perceba que a Ciência ocorre gradualmente e que recebe influências da cultura social da época. O que deve ser reconhecido, tanto por educadores como por cientistas, é que o Ensino de Ciências está intimamente ligado ao ensino da natureza do conhecimento científico (BIZZO, 1991).

A abordagem histórica do conhecimento permite construir uma visão de ciência em constante processo, permanentemente em transformação (LICATTI, 2005). Quando é dado o devido enfoque às ideias e normas predominantes de cada época antes da introdução de uma nova teoria, valoriza-se a construção da Ciência, ou seja, permite-se compreender o caminho percorrido pela contribuição dos diferentes personagens com discordantes concepções que auxiliaram, apoiando ou criticando a construção do conhecimento. Realizar essa relação entre o antigo saber para o novo saber é situar o aluno e não omitir a História e Filosofia da Ciência.

\section{Criações didáticas}

As criações didáticas podem ser configuradas em características elaboradas com o intuito de facilitar a aprendizagem de conceitos complexos, como imagens, esquemas, quadros explicativos, dentre outros (SILVA, 2017). A investigação de tais elementos foi efetuada mediante a indagação " 4 . Os livros apresentam criações didáticas para facilitar a compreensão da Evolução Biológica?”, cujos resultados compõem o Quadro 5. 
Quadro 5 - Análise das criações didáticas para a compreensão da Evolução Biológica

\begin{tabular}{|c|c|c|c|}
\hline \multirow[t]{2}{*}{ Código do livro } & \multicolumn{2}{|c|}{$\begin{array}{l}\text { Os livros apresentam } \\
\text { criações didáticas } \\
\text { para facilitar a } \\
\text { compreensão da } \\
\text { Evolução Biológica } \\
\end{array}$} & \multirow[t]{2}{*}{ Descrição } \\
\hline & Sim & Não & \\
\hline LD1 & & $\mathrm{X}$ & Não identificado. \\
\hline LD2 & & $\mathrm{X}$ & Não identificado. \\
\hline LD3 & $\mathrm{X}$ & & $\begin{array}{l}\text { Exibe o mapa da viagem de Darwin a bordo do } \\
\text { Beagle; aves do arquipélago de Galápagos e } \\
\text { também dos pombos domésticos. }\end{array}$ \\
\hline LD4 & & $\mathrm{X}$ & $\begin{array}{l}\text { O livro apresenta apenas as fotos de Lamarck, } \\
\text { Darwin e Wallace. }\end{array}$ \\
\hline LD5 & & $\mathrm{X}$ & Não identificado. \\
\hline LD6 & $\mathrm{X}$ & & Pescoço da girafa. \\
\hline LD7 & $\mathrm{X}$ & & $\begin{array}{l}\text { Usa ilustrações do alongamento do pescoço das } \\
\text { girafas para a teoria de Lamarck e Darwin; e } \\
\text { apresenta uma imagem referente a um ancestral } \\
\text { comum às aves das ilhas Galápagos. }\end{array}$ \\
\hline LD8 & $\mathrm{X}$ & & $\begin{array}{l}\text { Apresenta o exemplo do pescoço da girafa para } \\
\text { explicar a teoria de Lamarck e de Darwin; } \\
\text { apresenta o mapa da viagem de Darwin a bordo } \\
\text { do Beagle; cita como exemplo de seleção natural } \\
\text { as mariposas brancas e negras. }\end{array}$ \\
\hline LD9 & $\mathrm{X}$ & & $\begin{array}{l}\text { Ilustra como exemplo de seleção natural as } \\
\text { mariposas claras e escuras; como exemplo do } \\
\text { lamarckismo; publica fotos de Lamarck e Darwin. }\end{array}$ \\
\hline LD10 & $\mathrm{X}$ & & $\begin{array}{l}\text { O livro usa como exemplo as girafas para elucidar } \\
\text { as teorias de Lamarck e Darwin; cita um exemplo } \\
\text { de seleção artificial e natural. }\end{array}$ \\
\hline LD11 & $\mathrm{X}$ & & $\begin{array}{l}\text { O livro ilustra retratos de Lamarck e Darwin e a } \\
\text { capa do livro Origem das Espécies; apresenta o } \\
\text { mapa de toda a viagem a bordo do Beagle e mapa } \\
\text { das ilhas Galápagos; mostra imagens de alguns } \\
\text { seres vivos que ele encontrou durante os cinco } \\
\text { anos de viagem; destaca a árvore filogenética, } \\
\text { relacionando as aves de Galápagos e Ilha de } \\
\text { Cocos; ilustra a seleção artificial observada por } \\
\text { Darwin nos pombos. }\end{array}$ \\
\hline LD12 & $\mathrm{X}$ & & $\begin{array}{l}\text { Estampa as imagens de Lamarck. Darwin e } \\
\text { Wallace; ilustra um cladograma das aves de } \\
\text { Galápagos e exemplos de seleção natural. }\end{array}$ \\
\hline
\end{tabular}


Quadro 5 - Análise das criações didáticas para a compreensão da Evolução Biológica (continuação)

\begin{tabular}{|c|c|c|c|}
\hline \multirow[t]{2}{*}{ Código do livro } & \multicolumn{2}{|c|}{$\begin{array}{c}\text { Os livros apresentam } \\
\text { criações didáticas } \\
\text { para facilitar a } \\
\text { compreensão da } \\
\text { Evolução Biológica } \\
\end{array}$} & \multirow[t]{2}{*}{ Descrição } \\
\hline & Sim & Não & \\
\hline LD13 & $\mathrm{X}$ & & $\begin{array}{l}\text { Utiliza a figura de um peixe como exemplo da } \\
\text { teoria de Lamarck; apresenta uma escala de } \\
\text { organização dos seres vivos defendida por } \\
\text { Lamarck; um exemplar fóssil coletado por } \\
\text { Darwin e uma figura do navio Beagle; retratos de } \\
\text { Lamarck e Darwin e do livro Origem das Espécies } \\
\text { são apresentados. }\end{array}$ \\
\hline LD14 & $\mathrm{X}$ & & $\begin{array}{l}\text { Ilustra fotos de Lamarck, Darwin, Thomas } \\
\text { Malthus, Wallace, e dos livros Origem das } \\
\text { Espécies e Ensaio sobre o princípio da } \\
\text { população; imagem de um lagarto para } \\
\text { exemplificar o Lamarckismo; mapa de toda a } \\
\text { viagem a bordo do Beagle e mapa das ilhas } \\
\text { Galápagos; divulga a árvore filogenética das aves } \\
\text { de Galápagos e Ilha Cocos; descreve exemplo de } \\
\text { seleção artificial. }\end{array}$ \\
\hline LD15 & $\bar{X}$ & & $\begin{array}{l}\text { Mostra imagens de uma escultura da deusa grega } \\
\text { Atenas; há retratos de Buffon, Cuvier, James } \\
\text { Hutton e Charles Lyell, Darwin e Wallace; cita } \\
\text { exemplo das ideias de Buffon; mostra o esquema } \\
\text { das ideias de Lamarck; exemplo das girafas; mapa } \\
\text { do trajeto de Darwin. }\end{array}$ \\
\hline
\end{tabular}

Fonte: Elaboração pelas autoras.

Dos quinze livros analisados, apenas três (LD1, LD2 e LD5) não apresentaram nenhuma criação didática durante o desenvolvimento do conteúdo de Evolução Biológica.

Almeida e Falcão (2010) realizaram uma análise de livros didáticos de Biologia para comparar a área de alocação entre a teoria de Lamarck e Darwin. Os resultados mostraram que, entre as edições de 1965 a 1997, ocorreu um aumento considerável da área de texto e total, ou seja, os livros dedicaram mais espaço para os conteúdos evolucionistas de Lamarck e Darwin.

Nas edições mais recentes (2004 e 2006), o exemplo e a figura da girafa não estão presentes, talvez como resultado das críticas dirigidas a esse tema nos livros didáticos (BIZZO 1991; MARTINS, 1997; ALMEIDA; FALCÃO, 2010).

Referindo-se ainda às pesquisas efetuadas por Almeida e Falcão (2010), os pesquisadores também observaram que, entre os vinte livros didáticos analisados, treze 
(65\%) citam o exemplo do alongamento do pescoço das girafas, dentre os quais oito (40\%) são ilustrados. Como era de se esperar, a teoria de Darwin tem, nos livros didáticos de Biologia, uma área muito maior do que a teoria de Lamarck (ALMEIDA; FALCÃO, 2010).

O principal conceito referenciado pelos autores é a teoria da seleção, sendo uma unanimidade entre os autores (100\%), dos mais antigos aos mais atuais. Entretanto, o conceito de variações, intimamente associado por Darwin à seleção natural, é citado apenas por $75 \%$ dos autores (ALMEIDA; FALCÃO, 2010).

Entre as principais figuras dos livros didáticos, encontra-se a de Darwin, representado como um respeitável ancião de longas barbas brancas; raramente é representada sua imagem mais jovem, como no Biological Science Curriculum Studiy (BSCS) de 1965 e 1973. Outra figura comum é a do mapa da viagem do Beagle (ALMEIDA; FALCÃO, 2010).

As observações descritas por Almeida e Falcão (2010) puderam também ser contempladas nos livros LD4, LD9, LD11, LD12, LD13, LD14 e LD15, onde figuraram fotos dos pesquisadores com idade já avançada, provavelmente associando-os à ideia de sabedoria. Apenas no livro LD13 o autor da obra retrata Darwin na juventude. A maioria desses livros trazem as imagens apenas de Lamarck e Darwin como os principais idealizadores da teoria evolucionista.

Os mapas da viagem de Darwin estão presentes nos livros LD3, LD8, LD11, LD14 e LD15. Trazem como criações didáticas a Árvore Filogenética, comparando as aves de Galápagos com as aves da Ilha Cocos, quando Darwin percebeu que as semelhanças entre elas eram resultadas de uma ancestralidade em comum. De acordo com Chevallard (1991) apud Melzer (2012), essas criações podem auxiliar o aluno a compreender conceitos mais complexos, quando bem formuladas.

A seguir, exemplificamos algumas criações didáticas presentes nos livros didáticos. O livro LD3 apresenta esta imagem (Figura 6), cujo objetivo é representar os "experimentos" de Darwin com os pombos domésticos através da seleção artificial.

Os autores do LD3 retratam o mapa da viagem que Darwin fez a bordo do Beagle, elucidando a importância das observações a bordo do navio para a concepção de sua teoria (Figura 1). 
Figura 1 - Imagem retirada do livro LD3 (p. 164)

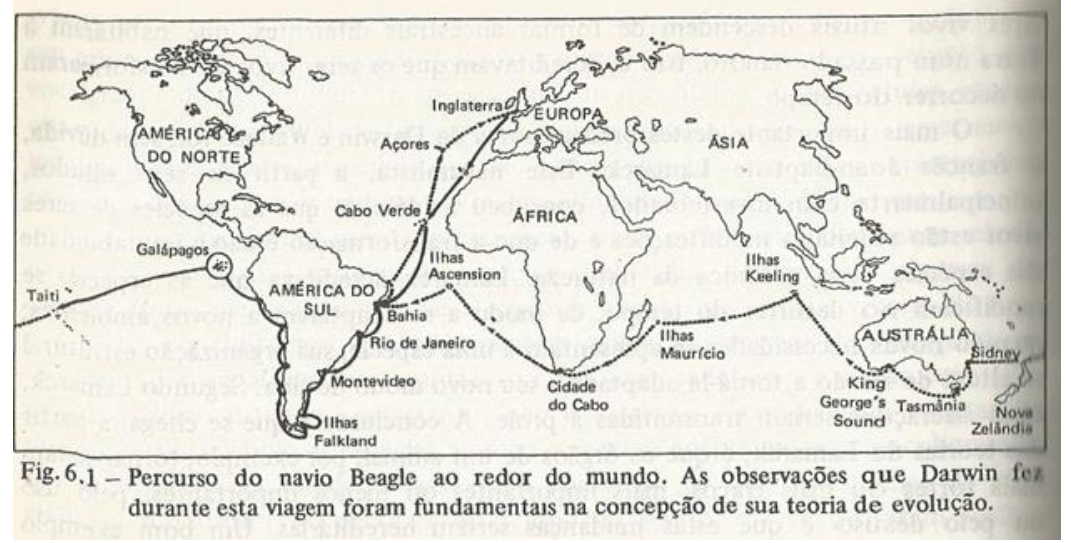

O livro LD4 retrata os pesquisadores Lamarck, Darwin e Wallace abaixo das suas respectivas teorias (Figura 2).

Figura 2 - Imagem retirada do livro LD4 (p. 136 e 137).
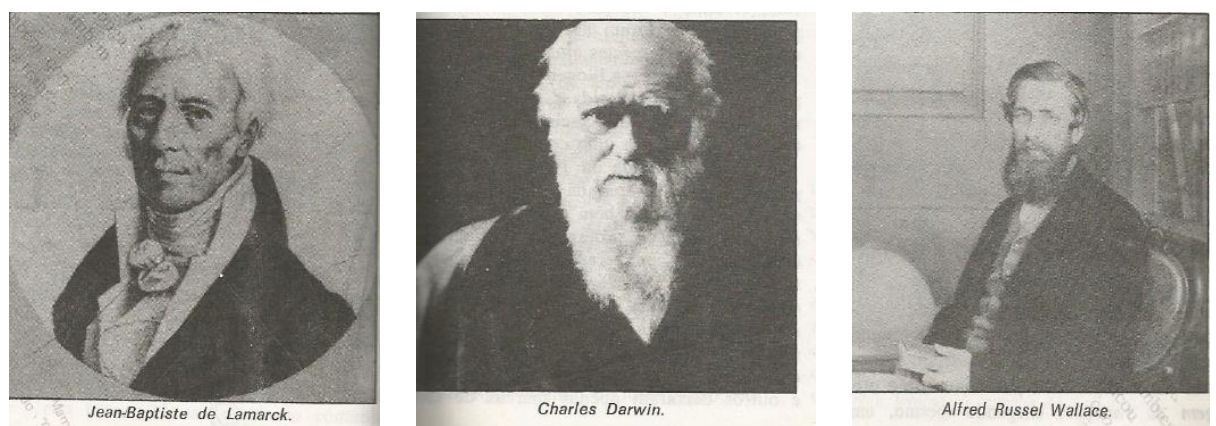

O livro LD6 traz como exemplo da teoria de Lamarck o alongamento do pescoço das girafas (Figura 3). A imagem da Figura 4, presente no livro LD7, também apresenta o alongamento gradativo do pescoço da girafa para a defesa da teoria de Lamarck.

Figura 3 - Imagem retirada do livro LD6 (p. 94).

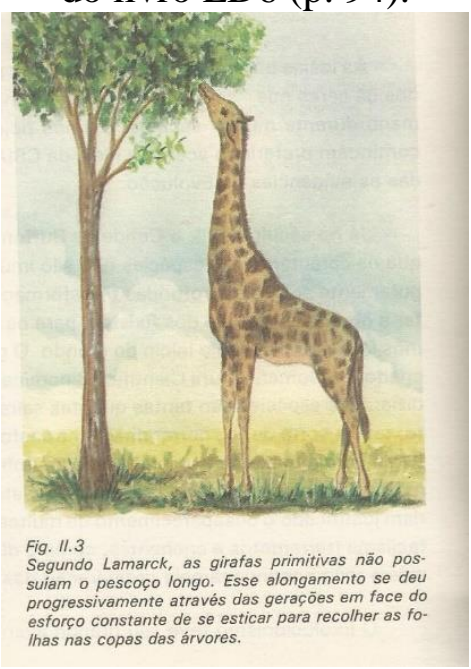

Figura 4 - Imagem retirada do livro LD7 (p. 382)

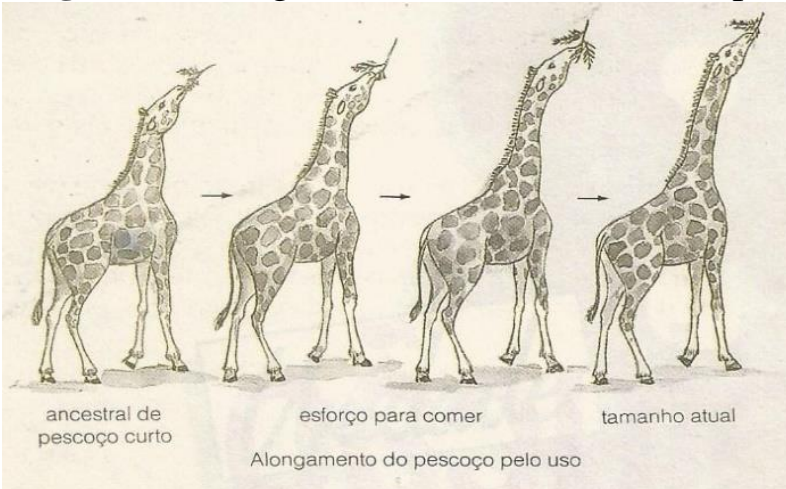


O livro LD7 também utiliza o exemplo do pescoço das girafas (Figura 5) para explicar a teoria da seleção natural proposta por Darwin.

Figura 5 - Imagem retirada do livro LD7 (p. 383).

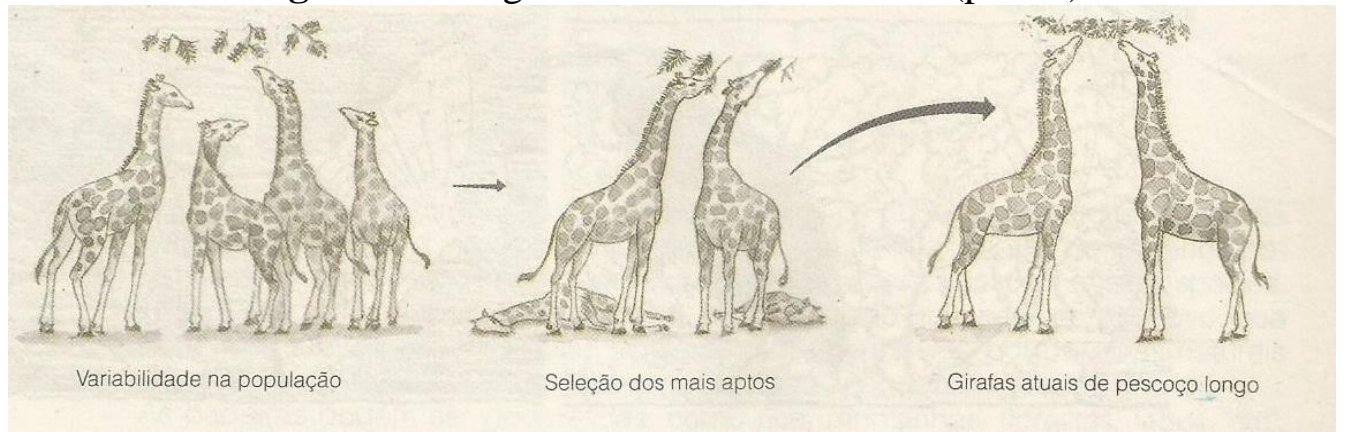

O LD14 retrata as obras de referência para o desenvolvimento da evolução biológica. A Figura 6 ilustra a obra de Thomas Malthus e a Figura 7, a obra de Charles Darwin.

Figura 6 - Imagem retirada do livro LD14 (p. 109).

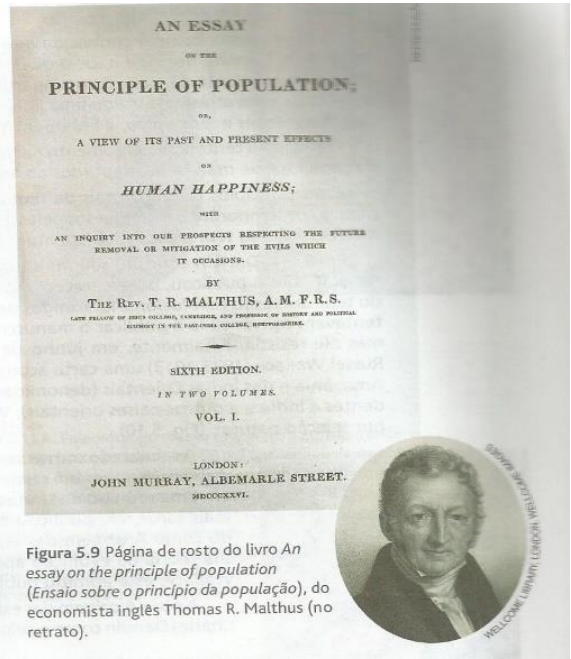

Figura 7: Imagem retirada do livro LD14 (p. 105).

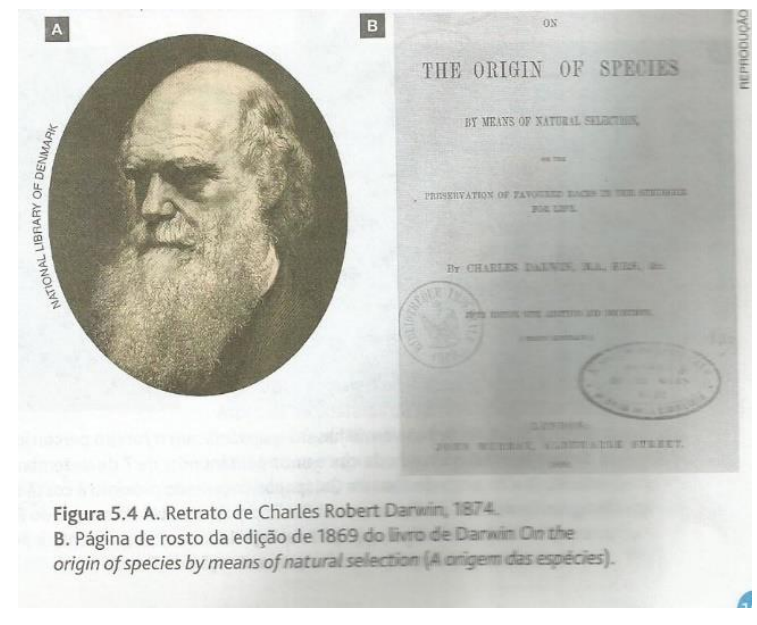

Os livros LD1 e LD2 não apresentam nenhuma criação didática. Sobre a ausência de imagens em trabalhos sobre evolução, Bizzo (1991) fez o seguinte comentário:

o fato de excluir as ilustrações da área total destinada ao tópico sugere que elas não sejam elementos importantes no processo de comunicação. É sabido que soluções visuais podem ser utilizadas para transmitir mensagens que, às vezes, $o$ tratamento textual se tornaria muito árido. Como exemplo corriqueiro pode-se citar o círculo: descrevê-lo é muito mais difícil do que mostrá-lo. Uma ilustração, neste caso, transmite muito mais fácil e precisamente o que se quer dizer em um texto (BIZZO, 1991, p. 239). 
Ao analisar as criações didáticas existentes nos livros, foi possível constatar que, no decorrer das décadas de 1980 a 2010, a tendência observada foi o acréscimo no número de imagens contidas nos livros didáticos que traziam exemplos interessantes para se compreender o tema, as imagens possuiam um efeito positivo na aprendizagem dos alunos.

Podemos observar, na análise dos quinze livros didáticos, que as imagens mais recorrentes são as referentes à Teoria de Lamarck e à Teoria de Darwin, pouco se fala sobre a influência dos outros pesquisadores.

Em sua pesquisa, Cicillini (1991, p. 56) constatou que o Darwinismo, mais conhecido como Teoria da Seleção Natural, é a concepção à qual os diferentes autores dedicam maior atenção, embora o façam de forma variada. Nos livros analisados, foi possível observar essa mesma tendência. Cicillini (1991, p. 58) constatou, em sua pesquisa, que as ilustrações relacionadas às diferentes concepções de evolução, em geral, refletem o texto didático na medida em que apresentam fotografias dos cientistas, mapas de viagem e, mais raramente, figuras que explicam uma dada concepção - geralmente essas figuras estão relacionadas com a Teoria da Seleção Natural.

$\mathrm{Na}$ análise das imagens retratadas nos livros examinados, observamos o mesmo padrão citado pela autora: as imagens mais recorrentes são da viagem a bordo do Beagle, do livro Origem das Espécies, dos pesquisadores Darwin e Lamarck e exemplos de suas teorias, principalmente utilizando a imagem das girafas.

\section{Considerações finais}

Analisamos os materiais didáticos de acordo com os elementos da transposição didática por meio de questionamentos e observamos que o conteúdo de Evolução Biológica é abordado descontextualizado e desatualizado do saber original.

Com relação à fidelidade do saber, chamam a atenção algumas metáforas comumente utilizadas nos depoimentos de alunos e professores e também transcritas nos livros didáticos que geram concepções equivocadas. Outras ideias que reforçam esses equívocos estão relacionadas à teoria de Darwin e Mendel e à simplificação denotada a Lamarck.

Quanto ao envelhecimento biológico e moral, notamos um distanciamento e demora na atualização dos conteúdos relacionado à evolução. Com a análise da relação antigo/novo do saber, percebemos que a maioria resgata o conhecimento aceito anteriormente à consolidação da Evolução Biológica, sendo esse um ponto positivo para evitar a transmissão dos conhecimentos como prontos, acabados e definitivos. 
Nas criações didáticas, a imagem do pescoço da girafa foi majoritariamente retratada pelos autores para o estudo da teoria de Lamarck. Na área de textos, a ênfase é direcionada para as teorias de Darwin, sendo fortalecidas pelas imagens do Beagle, do bico das aves de Galápagos e também pela vasta figura da sua obra: Origem das Espécies. Praticamente em todas as obras, as imagens de Lamarck e Darwin se fizeram presentes, reforçando uma visão individualista da construção do conhecimento científico. Essas figuras pouco contribuem para o desenvolvimento do pensamento evolutivo e algumas delas até limitam a compreensão correta do desenvolvimento da Ciência.

No decorrer das décadas, na comparação das obras de 1970 com as de 2010, identificamos um aperfeiçoamento nas criações didáticas, os conceitos e a História da Ciência ganharam mais fidelidade do saber. Contudo, mais pesquisas e discussões sobre a formulação dos livros didáticos permitirá a veiculação do conhecimento na integralidade.

Azevedo e Motokane (2011) defendem que os alunos compreendam o conhecimento a partir do processo de sua construção, sem olhar somente para o produto final. Nota-se tal argumentação no fragmento:

\begin{abstract}
ao trabalhar com os alunos a história da teoria evolutiva, o professor tem em mãos um excelente aparato para desconstruir essa imagem neutra, imparcial e desvinculada da sociedade que os alunos têm da Ciência e apresentá-los a Ciência como uma atividade humana e os cientistas como agentes que têm interesses políticos, econômicos e sociais. Com esse tipo de abordagem, que mostra que a Ciência é permeada por paradigmas, os alunos teriam a chance de enxergar que ela não detém todas as respostas, e que é, acima de tudo, uma atividade social, construída coletivamente, e não por mentes brilhantes trabalhando sozinhas. Assim, os alunos teriam a oportunidade de perceber a transitoriedade dos conhecimentos científicos, posicionar-se em relação a questões polêmicas e entendê-los como parte da história humana (AZEVEDO; MOTOKANE, 2011, p. $3)$.
\end{abstract}

Ressaltamos a importância de abordar a História e Filosofia da Ciência, pois ao demonstrar todo o processo de construção do conhecimento científico, os problemas, os erros, as influências, os medos e anseios dos cientistas, as perguntas, a importância, a motivação, entre outros, desfaz-se a imagem equivocada de Ciência de que essa é construída somente por gênios.

\title{
Referências
}

Almeida, V. A., \& Falcão, R. T. J. (2010). As teorias de Lamarck e Darwin nos Livros Didáticos de Biologia no Brasil. Ciência e Educação, Bauru, v. 16, n. 3, p. 649-665. 
Araújo, H. I., \& Porpino, K. O. (2010). Análise da abordagem do tema Paleontologia nos livros didáticos de Biologia. Anuário do Instituto de Geociências - UFRJ. Rio de Janeiro.

Azevedo, C. R., \& Motokane, T. M. (2011). A evolução nos livros didáticos do Ensino Fundamental aprovados pelo MEC: uma reflexão a partir da análise de duas coleções. In: VIII ENCONTRO NACIONAL DE EDUCAÇÃO EM CIÊNCIAS. VII., Anais [...]. VIII ENPEC.

Bizzo, V. M. N. (1991). Ensino de evolução e história do Darwinismo. 1991. 494f. Tese (Doutorado em Educação). Universidade de São Paulo, Faculdade de Educação, São Paulo.

Bizzo, N., \& El-Hani, N. C. (2009). O arranjo curricular do ensino de evolução e as relações entre os trabalhos de Charles Darwin e Gregor Mendel. Filosofia e História da Biologia, São Paulo, v. 4, p. 235-257.

Brasil (2006). Ministério da Educação. Secretaria de Educação Básica. Orientações Curriculares para o Ensino Médio - Ciências da Natureza, Matemática e suas Tecnologias. Disponível em: http://portal.mec.gov.br/seb/arquivos/pdf/book_volume_02_internet.pdf. Acesso em: 14 fev. 2021.

Carvalho, S. G. (2009). A Transposição Didática e o Ensino da Biologia. In: Caldeira, A. M. A., \& Aaraújo, N. N. S. E. Introdução à Didática da Biologia, São Paulo: Escrituras Editora, p. 34-51.

Chartier, R. (1990). A história cultural entre práticas e representações. Lisboa: Difel. 248 .

Cicillini, G. A. (1991). A Evolução enquanto um componente metodológico para o ensino de Biologia no $2^{\circ}$ grau: análise da concepção de Evolução nos livros didáticos. 143f. Dissertação (Mestrado em Educação) - Faculdade de Educação, Universidade Estadual de Campinas, Campinas.

Corrêa, R. L. T. (2000). O livro escolar como fonte de pesquisa em história da educação. Cadernos CEDES, Campinas, v. 20, n. 52, p. 11-23.

Gil-Perez, D., Montoro, F. I., Alís, C. J., Cachaapuz, A., \& Praia, J. (2001). Para uma imagem não deformada do trabalho cientifico. Ciência e Educação, Bauru, v. 7, n. 2, p. 125-153.

Licatti, F. (2005). O ensino de Evolução Biológica no nível Médio: investigando concepções de professores de Biologia. 240f. Dissertação (Mestrado em Ensino de Ciências). Universidade Estadual Paulista, Campus de Bauru, Bauru.

Martins, L. A. C. P. (1997). Lamarck e as quatro leis da variação das espécies. Episteme, Porto Alegre, v. 2, n. 3, p. 33-54.

Martins, L. A. C. P. (1998). A História da Ciência e o Ensino da Biologia. Ciência e Ensino, Campinas, n. 5, p. 18-21.

Meglhioratti, A. F. (2004). História da Construção do Conceito de Evolução Biológica: possibilidades de uma percepção dinâmica da Ciência pelos professores de Biologia. 272f. Dissertação (Mestrado em Educação para Ciência). Faculdade de Ciências da Universidade Estadual Paulista "Júlio de Mesquita Filho", Campus de Bauru, Bauru. 
Melzer, M. E. E. (2012). Do saber sábio ao saber a ensinar: Transposição Didática dos modelos atômicos nos livros de Química (1931- 2012). 554f. Dissertação (Mestrado em Educação em Ciências e em Matemática). Pós-Graduação em Educação em Ciências e em Matemática, Setor de Ciências Exatas, Universidade Federal do Paraná, Curitiba.

Neves, R. C. K. (2009). Um Exemplo de Transposição Didática: o caso das Matrizes. 163f. Dissertação (Mestrado em Educação para Ciência e Matemática). Universidade Estadual de Maringá, Maringá.

Pena, G. A. de C. (2014). Docência na Educação Profissional e Tecnológica: conhecimentos, práticas e desafios de cursos técnicos na Rede Federal Belo Horizonte. 290f. Tese (Doutorado em Educação) - Faculdade de Educação, Universidade Federal de Minas Gerais.

Pinho Alves Filho, J. (2000a). Atividades Experimentais: do método a prática Construtivista. 448f. Tese (Doutorado em Educação). Pós-Graduação em Educação, Universidade Federal de Santa Catarina.

Pinho Alves Filho, J. (2000b). Regras da Transposição Didática aplicadas ao laboratório didático. Cad. Cat. Ens. Fís., Florianópolis, v. 17, n. 2, p. 174-188.

Silva, A. A. (2017). Conceitos e Transposição Didática de Genótipo e Fenótipo: uma análise de livros didáticos. 122f. Dissertação Mestrado em Educação. Pós-Graduação em Educação, Universidade Estadual do Oeste do Paraná/UNIOESTE - Campus de Cascavel, Cascavel.

Silva, R. M., \& Trivelato, S. L. F. Os livros didáticos de biologia do século XX. In: ENCONTRO NACIONAL DE PESQUISA EM EDUCAÇÃO EM CIÊNCIAS, 2. 1999, Bauru. Atas [...]. Bauru, 1999.

Thomaz, D. (2012). Do livro didático ao aluno: transposição didática na aula de Matemática do Ensino Médio Diurno e Noturno. 211f. Dissertação (Mestrado em Educação). Instituto de Educação, Programa de Pós-graduação em Educação, Universidade Federal de Mato Grosso, Cuiabá.

Unesco (2020). A Comissão Futuros da Educação da Unesco apela ao planejamento antecipado contra o aumento das desigualdades após a COVID-19. Disponível em: https://pt.unesco.org/news/comissao-futuros-da-educacao-da-unesco-apela-aoplanejamento-antecipado-o-aumento-das. Acesso em: 4 jun. 2020

Vasconcelos, D. S., \& Souto, E. (2003). O livro didático de Ciências no Ensino Fundamental - Proposta de critérios para análise do conteúdo zoológico. Ciência e Educação, Bauru, v. 9, n. 1, p. 93-104. 
Autoras

Bianca Guimarães Severo dos Santos

Licenciada em Ciências Biológicas pela Universidade Estadual do Paraná, (2017), Mestrado em Ensino Formação Docente Interdisciplinar pela Universidade Estadual do Paraná, (2020), Pós graduada em Educação Ambiental pela Faculdade Educacional da Lapa (2020), Licenciada em Pedagogia pela UniBF (2021). Professora do Colégio Estadual Lúcia Alves de Oliveira Schoffen

Email: severobfg@gmail.com https://orcid.org/0000-0002-6146-4699

Lucila Akiko Nagashima

Doutorado em Engenharia Química Ex-docente do Programa de Pós-Graduação em Formação Docente Interdisciplinar Universidade Estadual do Paraná (UNESPAR), Campus Paranavaí, PR. Brasil.

E mail: lucilanagashima@uol.com.br https://orcid.org/0000-0001-8197-9668

\section{Como citar o artigo:}

SEVERO, B. G.; NAGASHIMA, L. A. Transposición Didáctica de la Evolución Biológica: análisis de los libros didácticos. Revista Paradigma Vol. XLII, Nro. 2, Diciembre de 2021 / $27-52$.

DOI: https://doi.org/10.37618/PARADIGMA.1011-2251.2021.p27-52.id1050 